\title{
Effective Rapport in Tourist Guiding (Interpretation of Themes)
}

\section{Sherine El-Menshawy*}

Department of Ancient History, Qatar University, Doha, Qatar

Corresponding author: Sherine El-Menshawy, Associate Professor of Ancient History, PhD, College of Arts and Sciences, Qatar University, Doha, Qatar, Tel: (+974) 4403-4714; E-mail: Sherymenshawy@qu.edu.qa

Rec date: May 19, 2016; Acc date: June 14, 2016; Pub date: June 17, 2016

Copyright: () 2016 El-Menshawy S. This is an open-access article distributed under the terms of the Creative Commons Attribution License, which permits unrestricted use, distribution, and reproduction in any medium, provided the original author and source are credited

\begin{abstract}
The aim of this paper is to discuss the requirements for effective guiding and the attributes for establishing effective rapport in tourist guiding. The paper will suggest an "interpretation of themes," using a thematically oriented approach in order to help tourist construct meaning, by giving an example of manicure and pedicure scenes in Ancient Egypt. This will be followed by arguments on the importance of interpretation of themes as part of the art and creativity of guiding, which should be added to the tourist guiding profession, and which will assumingly influence the tourists' construction of meaning for their experiences.
\end{abstract}

Keywords: Tourist guide; Requirements for effective guiding; Attributes for effective rapport; Interpretation of themes

\section{Introduction}

Cultural tourism [1] is a method to introduce national individuality that centers on historical sites. It includes visits to historical sites and museums and even attendance at conventional festivals. It emerges from an interest for learning about the past or about historical cultures. It attracts those tourists who normally have a sense of exploration and detection and who frequently desire exceptional experiences. Cultural tourism raises awareness and appreciation of cultural heritage while encouraging tourists to visit historical archeological sites. It is a profitable industry that supports local businesses including hotels, restaurants and local crafts besides allowing number of job opportunities, which helps in public and regional expansion [2]. Presenting such historical and cultural heritage, however, requires a well-trained tourist guide.

Tourist guiding only became a recognized profession in the fiftieth year of the Twentieth Century. For a long time the occupation was practiced by laymen who possessed some knowledge of a foreign language and some mythical information on heritage sites. The main role of current tourist guides is to provide information, principally at the commencement of tourists' visits to a certain destination [3]. They may, however, have multidimensional roles and sub-roles [4]; including knowledge supplier, mediator, promoter, publics mover, instructor, security captain, tourism ambassador, public affairs representative, humorous, difficulty dealer and social worker [5]. McGrath [6] distinguished between the roles of "original guide" as information giver and the "guide-interpreter" who would compare, analyze etc.

Quality information and interpretation that tourist guides offer to visitors may encourage the visitors to be more interested in taking up additional tourist activities that offer new, extraordinary, different, and exciting situations, thus encouraging and enabling them to extend their planned stays and thus consume more. The quality of the information provided to tourists depends on the individual guide, based on the guide's personal education and professionalism.
Conversely, tourists are becoming more knowledgeable and demanding, and if the tourist guide is less educated than the tourists, it will presumably reflect on the visitor's contentment, which may also affect his opinion about the tourist guide's proficiency and the length of his planned stay.

\section{Requirements for Effective Guiding}

A tourist guide is a person who guides visitors in the language of their choice and explains the cultural and natural heritage of an area to ease understanding its meanings.

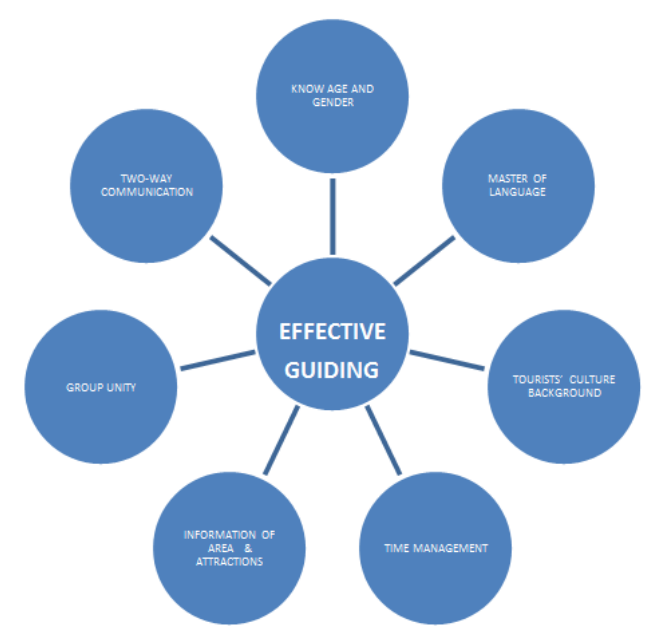

Figure 1: Requirements for effective guiding.

Though, roles of tourist guides are varied composing sub-roles including interactive, social and communicative responsibilities [7]. The profession of tourist guiding is sometimes seen as information giving or repetition of information [8], although it can be an effective device in the formation of tourist knowledge; hence, effective guiding is built on the following requirements (Figure 1). 


\section{Tourists' cultural background}

The tourist guide should be aware of the tourists' social, economic and cultural background to be able to respond with the type of information and presenting style that suits the tourists best; therefore, it is argued that bi-cultural guides are more capable than monocultural [9].

\section{Master of language}

The guide should speak a range of languages in order to communicate easily. Tourist guide should speak fluently, clearly, audibly and with confidence. A guide may even teach his guests a few phrases so that they feel at home.

\section{Reacting to consumer needs}

It is of particular importance to understand and react according to the consumer needs in order to provide a product that satisfies customer requirements. For example, knowing the age and gender of the tourist is a factor that might influence visitor satisfaction. In developing market strategies, younger visitors may require more excitement and variety and thus have higher expectations of the tourist attractions, thus experiencing lower levels of satisfaction than older visitors [10].

\section{Considering the needs of the tourist industry}

Delivery of information related to an area and its attractions should be tailored to the business and operational needs of the tourism industry. The guide should have an extensive knowledge of the history and role of the visited site [11]. Conveying the tourist guide's enthusiasm and passion to the group can make the site really come alive and can enhance each tour member's general understanding of the site. For example legends of the areas are interesting whether they are open or closed areas.

\section{Time management}

Time allocated for guiding is essential since the tourist guide should be good time keepers since these tours vary in duration but range from half a day to two or more.

\section{Group unity}

A tourist guide should make sure that the tourist's moves in unity from one place to another without missing a single tourist [12].

\section{Two-way communication with audience}

Flexible communication and a friendly manner are essential to make a great tour. Exchange of information can also be a good form of communication while attracting the visitors' interest through concepts that relate to their interests. Finally, a tourist guide is expected to provide the visitors with factual and accurate information giving a better understanding of the culture and the people.

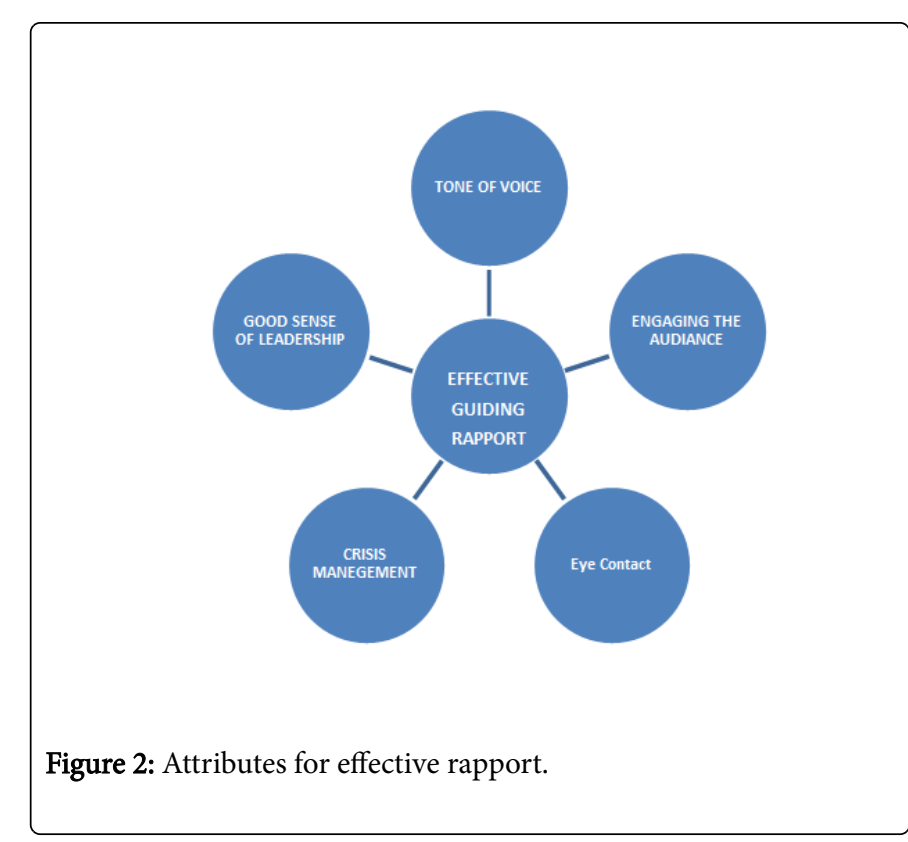

\section{Constructing rapport}

Construction rapport is the basis of any good connection and how to shape strength, deepness and confidence in their relation with visitors (Figure 2). Rapport includes the following attributes:

Eye contact: When addressing the group, the tourist guide should turn his back to the object-church, architecture, sculpture, or whatever. $\mathrm{He}$ should talk to the group with eye contact. Some tourist guides refuse to wear sunglasses for this reason.

Engaging the audience: Tourist guides should share their knowledge in an engaging, illuminating and entertaining way, rather than repeating a list of facts. A tourist guide could engage the tourists by asking them some questions, such as what would you like to know about...? Do you have any queries? and even How was the tour?

Tone of voice: The tone of voice should be loud and clear and not too fast or too slow.

Good sense of leadership: A certain degree of authority is required to keep all the visitors together and focused.

Crisis management: Sometimes a tourist guide may encounter problems; however, he should use appropriate tactics to deal with the situation.

Accurate facts: Finally, tourist guide is expected to provide the visitors with factual and accurate information giving a better understanding of the culture and the people.

\section{Interpretation of a Theme as an Art of Guiding and Creativity}

Cohen's publication in 1985 [13] has attracted the attention to the scientific role of the professional tourist guide. Cohen pointed out the effect of interpretation identifying that "the term with intercultural mediation, explaining it as translation of foreign and unknown elements of the host culture into a cultural idiom which is close to the guest". 
The encyclopedia of tourism stated that interpretation is "any activity which seeks to explain to people the significance of an object, a culture or a place" [14]. american national association for interpretation (NAI) explained: "Interpretation is a mission-based communication process that forges emotional and intellectual connections between the interests of the audience and the meanings inherent in the resource" [15]. Heritage interpretation [16] allows transferring symbolic meanings which emphasis the importance to the presented cultural and historical subject at a destination. This enhances enjoyment and satisfaction and mirrors appreciation and a positive influence on tourists and visitors [17].

The following discussion is a practical example of interpretation of a theme. In this example one will explore the theme Pedicure and Manicure in Ancient Egypt, here the guide would give an introduction about the topic as follows.

Illustrations of manicure and pedicure are rare in ancient Egypt, yet evidence has been found from a scene discovered in a chapel tomb at Saqqara located some 30 kilometers south of Cairo. The individuality of Saqqara is for its continuous usage from the first dynasty (c. $3050-2850$ BC.) throughout the early Christain era, the 5th century CE. The expansion of Saqqara is of main interest since it comprises evidences of the history of Memphis as administrative, monetary, and religious focus [17]. Thousands of people throughout the ages were buried at Saqqara. Although many of their tombs still lie hidden beneath the sands, a large number have been discovered and excavated, and their decoration has provided scholars with enormous amounts of information about daily life and death in ancient Egypt. The chapel tombs in Saqqara belong to nobles and high-ranking government officials. In the Old Kingdom the kings were buried in the pyramids and not in normal tombs and no depictions of kings from this period have been found. Presumably, then, they were just never depicted at all, possibly out of respect for their ideological role in the society [18].

The scene (Figure 3) is located on the north wall of the doorway room in the tomb of Niankhkhnum (meaning "life belongs to the god Khnum") and Khnumhotep (meaning "the god Khnum is satisfied"). It is also known as the "Tomb of the Hairdressers" and "The Tomb of Two Brothers". It dates to the Fifth Dynasty (ca. 2465-2323 BC.) of the Old Kingdom. Both men shared the titles "Prophet of Ra in the Sun Temple of Niusserre," and "Heads of the Manicurists of the Great House". This tomb was discovered in 1964 by archaeologists and Chief Inspector Mounir Basta, under the ramp of King Unas [19].

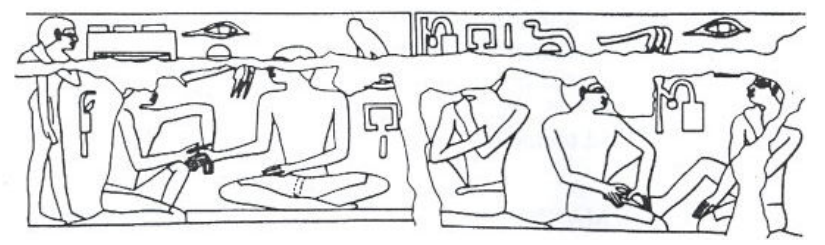

Figure 3: Scene from the tomb of Niankhkhnum and Khnumhotep published after (Moussa und Altenmüller, 1977).

A collective description of the scene includes the following explanation:

On the right side a man is shown on the floor in a squatting position, placing his foot on the knee of a second man. The second seems to be doing pedicure with the first man's foot. The symbol for "scribe" appears in between these two men, and the symbol for "doer of the nails" appears above them. To left of these two men, there is a third man, seated, underneath another symbol for "scribe". To the left of this third man, there is a symbol for "overseer of the house". To the left of that symbol there is a fourth man sitting cross-legged on a slightly raised platform and extending his hand, which is being held by a fifth man probably for doing manicure. This fifth man also appears to be holding a small object in his right hand. Another symbol for "doer of the nails" appears over these two men, along with what appears to be a toilet box. The symbol for "follower" appears to the left of the fifth man, and to the left of this symbol there is a sixth man in a standing position. This sixth man appears to be naked, while the other men are wearing waist-clothes.

\section{In this stage argumentation would raise the following questions.}

Is this an activity that was practiced by both genders?, the available evidence is inadequate to answer whether this activity was practiced by both genders. This scene does not depict any women engaged in the activity; but this is not sufficient to conclude women did not do it. We need to ask the following further questions: Have women been depicted doing manicures/pedicures, in any other scenes? If yes, we have our answer. If no, then we should ask: Have women been depicted in any scenes at all? If no, then such scenes would tell us nothing about what women did nor did not do. If yes, then: How many manicure/ pedicure scenes have been discovered? The depicting this activity that have been discovered, then the greater the likelihood that only men engaged in the activity.

Did this activity involve a hierarchy?, this activity did involve a hierarchy. The symbol for "follower" appears on the left; The man depicted next to this symbol is not wearing a waist-cloth; The other men are wearing a waist-cloth; Therefore, the "follower" is lower in social class than the others, The "follower" is next to the toolbox so Likely, he carries or cares for the tools. There was an "overseer of the doer of the nails;" therefore, this activity involved a hierarchy.

What is the social status of the people engaged in this activity?, the people engaged in this activity are upper-middle class. The terms, "scribe" and "overseer of the house," are displayed next to the customers and these are upper-middle class jobs since the customers and manicurists are wearing waist-clothes, which indicate a middle class. Therefore, the people involved in this activity are upper or middle class.

Did the kings engage in this activity?, the kings did receive manicure/pedicure. Evidence comes from titles inscribed during the fifth Dynasty [20]. It includes: "Doer of the Nails of the Great House". The "Great House" refers to the royal palace; therefore, it is likely that the king had his nails done, since these titles spotlight on sensitive positions of men dealing with the king's toilet.

What is the scene telling us about the tools that were used in this activity?, the second figure from the left is holding a rasp or file in his right hand, also there is a toilet box for keeping cosmetic tools; therefore, the manicure/pedicure process likely involved tools. Since manicures/pedicures today involve nail files, it is likely that the object in question is a file.

\section{Discussion}

In the above example, the guides help tourists make connections with history and culture by attracting their attention by interpreting a 
theme [21] that includes variant subjects as the pedicure and manicure activities gender and hierarchy, highlighting the social status of the people engaged in this activity, questioning the engagement of kings in this activity, and inquiring about the tools that were used [22]. Interpretation is well attained when linking themes and places with concepts and meanings, and also when connecting new ideas with information adapted to the visitors' knowledge, which adds an entirely special meaning and sense to the theme and ends up with the emerging the tourist in an interpretation environment [23]. McGrath [24] mentioned that: "The role of the guide then in a post-modern context is to introduce something additionally, something that visitors cannot obtain via any other media as well as to expand the traditional pathfinders aim of providing, access to an otherwise non-public terrain to the encompass the intellectual terrain locked and otherwise inaccessible".

Using a thematically oriented approach is a way to involve visitors in understanding the history and the culture. Pond declared that "theme interpretation relies on the fact that the topic can persuade the audience or provoke positive reactions in an individual: knowledge, feeling (empathy) and (action);" [25] therefore, incorrect, unconvincing or misinterpreted topics will detracts the overall enjoyment for visitors. Personal face-to-face interpretation influences the tourists, which may lead to their contact with the tourist guide and the presented theme. The tourist guide must therefore present quality interpretation that requires wide-ranging knowledge on the subject, and presentation skills, with a high level of communication in a flexible approach that logically would be met by a qualified tourist guide. This would be attained by complementing theoretical knowledge with concrete skills.

The personal attentiveness and enthusiasm of the tourist guide stimulates visitors' engagement in a topic and can convey the guide's enthusiasm to the group. Grinder and McCoy [26] stated that "Tour guide's enthusiasm, skillfulness, desire, and willingness to share information can help visitors, young and old, make connections between their own lives and valued artifacts, art objects, and history as represented by museum collections" [27]. Cohen [28] stated that "Interpretive tourist guides can transfer tourists from the sphere of unknown into the sphere of known by using cultural patterns and idioms that tourists are familiar with". It can be argued that "Interpretation is an act of creativity," which is defined as "a mental and social process involving the generation of new ideas or concepts, or new associations of the creative mind between existing ideas or concepts...An alternative conception of creativeness is that it is simply the act of making something new" [29]; therefore, by interpreting scenes using originality, a tourist guide can transfer knowledge into a product of creativity.

\section{Conclusion}

Raising visitors' satisfaction can be through interpretation of themes, which encourages their interaction and communication to express their opinions and observation abilities [30]. Consequently, interpretation can build a bridge of discussion, with the tourist composing a range of feedback data. Appropriate and accurate interpretation involves training tour guides who should be integrated into cultural tourism programs [31]. Pond [32] argued that tourist guides' interpretations should be regarded as an essential part of service quality, as they should be ready playing "the role of the interpreter of nature, history and heritage in general," yet, one would add "interpretation of themes" as a key component of tourist guide profession.

\section{Acknowledgements}

I am indebted to Dr. Mohamed Saleh, the former General Director of the Egyptian Museum in Cairo, for his endless support throughout my academic life. My thanks are extended to my colleagues at the Faculty of Tourism and Hotels, Alexandria University for their continuous help and support always. I am grateful to Dr. Nancy Allan, visiting Professor, Qatar University for reading the final version and making useful comments.

\section{References}

1. McKercher B, du Cros H (2002) Cultural Tourism: the Partnership between Tourism and Cultural Heritage Management, Routledge, 262.

2. Manson P, Douglas C (2012) Tourism Impacts, Planning and Management Tourism and Archaeological Heritage Management at Petra: Driver to Development or Destruction? New York, USA.

3. Holloway (1993) The Guided Tour Kathleen Pond, The Professional Guide: Dynamics of Tour Guiding, John Wiley \& Sons 377-402

4. Zhang H, Chow I (2004) Application of importance-performance model in tour guides' performance: evidence from mainland Chinese outbound visitors in Hong Kong”, Tourism Management 25:81-91, Rosemary Black, Betty Weiler (2005) Quality Assurance and Regulatory Mechanism in the Tour Guiding Industry: A systematic review Journal of Tourism Studies 16(1), 24-36.

5. Weiler CB, Davis D (1993) The Tourist Guide, An Exploratory Investigation into the Roles of the Nature-based Tour Leader, Tourism Management 14: 91-98.

6. http://www.smuc.ac.uk/Courses/Schools/Management-Businessenterprises/presentation_18407ppt.pdf (pristup: 05/2008)

7. Holloway C (1981) "The Guided Tour: A Sociological Approach", Annals of Tourism Research 12: 377-402.

8. Holloway, "The Guided Tour”, 377-402.

9. Pearce P (2005) Tourist Behavior: Themes and Conceptual Schemes Nesa Wu and Mcpartlin Haywood, The Need for Cultural Brokerage: A Study of Canadians Visiting China and the Tour Operators Who Facilitate Trips Canada, USA 11-12.

10. Zeithaml VA, Parasuraman A, Berry LL (1990) Delivering Quality Service-Balancing Customer Perceptions and Expectations, New York, USA.

11. McDonnell I (2001) "The Role of the Tour Guide in Transferring Cultural Understanding”, Working Paper No. 3, School of Leisure, Sport and Tourism, University of Technology, Sydney.

12. Jennings G, Nickerson N (2006) Quality Tourism Experiences Oxford 14.

13. Cohen E (1985) The Tourist Guide: The Origins, Structure and Dynamics of a Role, Annals of Tourism Research 12: 5-29.

14. Jafari J (2007) Encyclopedia of Tourism London and New York 327.

15. http://www.interpnet.com/, accessed 20/5/08

16. Russell S, Robyn B (2003) Travel Knowledgeably: The Question of Content in Heritage Interpretation", in: Rosemary Black and Betty Weiler, Interpreting the Land Down Under: Australian Heritage Interpretation and Tour Guiding (opens in new window), Colorado USA. 92-108.

17. Vukonic B (2008) Povijesni gradovi i njihova turisticka razvojna opcija (Historic Towns and Their Tourism Development), Acta Turistica Nova 2: 111-122.

18. Hornung E (1997) The Pharaoh, in Donadoni, Sergio The Egyptians Chicago, USA. 284.

19. Moussa A, Altenmüller H (1977) Das Grab des Nianchchnum und Chnumhotep. Old Kingdom Tombs at Causeway of King Unas at Saqqara, Mainz am Rhein 29. 
Citation: El-Menshawy S (2016) Effective Rapport in Tourist Guiding (Interpretation of Themes). J Socialomics 5: 172. doi: 10.4172/2167-0358.1000172

Page 5 of 5

20. Mariette A (1889) Les Mastabas de l'Ancien Empire, Heidelberg, 406 (E 11).

21. Pastorelli J, Ham S, Weiler B (2003) Enriching the Experience; An Interpretive Approach to Tour Guiding Australia, Interpretation is persuasive when themes are compelling, Interpret Scotland 8: 3-4.

22. Brochu L, Merriman T (2002) Personal Interpretation: Connecting Your Audience to Heritage Resources Singapore 3.

23. Rabotic B (2007) Turisticki vodici kao medijatori u kulturnom turizmu (Tour Guides as Mediators in Cultural Tourism)“, in: Hotelplan 2007, The Third Biennial International Congress, 23-24 November 2007, The College of Hotel Management, Beograd 1041-1047, Russell Staiff, Robyn Bushell (2003) Travel Knowledgeably: The Question of Content in Heritage Interpretation". In: Black R, Weiler B (Eds). Interpreting the Land Down Under: Australian Heritage Interpretation and Tour Guiding (opens in new window) Colorado 2003: 92-108.

24. http://www.smuc.ac.uk/Courses/Schools/Management-Businessenterprises/presentation_18407ppt.pdf (pristup: 05/2008)

25. Pond K (1993) The Professional Guide: Dynamics of Tour Guiding John Wiley \& Sons 143
26. Knudson DM, CableTT, Beck L (2003) Interpretation of Cultural and Natural Resources, Pennsylvania 10.

27. Tilden F (1977) Interpreting Our Heritage, (3rdedn) North Carolina, 94.

28. Cohen (2000) The Tourist Guide 5-29.

29. http://www.ecotourismglobalconference.org/wpcontent/uploads/2007/06/ III.3.\%20Erick\%20Vargas.pd

30. Rabotic B, Turisticko vodenje u savremenom turizmu (Tourist Guiding in Contemporary Tourism), (unpublished doctoral dissertation, Belgrade University, 2009); Erick Vargas, "Effective nature and culture interpretation for quality ecotourism experiences.

31. Chow Z (2002) Application of importance-performance model, Sam Ham and Betty Weiler, Tour Guide Training: A Model for Sustainable Capacity Building in Developing Countries" Journal of Sustainable Tourism 10: 52-69.

32. Pond, The Professional Guide, 143. 